\title{
Ética Científica y uso de material o datos colectados de seres humanos
}

Programa de Genética Humana, ICBM, Facultad de Medicina, Universidad de Chile.

Recibido el 14 de abril de 2011, aceptado el 18 de octubre de 2011.

Corresondencia a: Carlos Y Valenzuela Programa de Genética Humana, ICBM, Facultad de Medicina, Universidad de Chile. Independencia 1027, Casilla 70061, Independencia, Santiago, Chile. FAX (56-2) 7373158 Fono (56-2) 6786302 E-mail: cvalenzu@med. uchile.cl

\author{
CARLOS Y. VALENZUELA
}

\section{Scientific ethics and the use of human material or data}

A scientific article censured by superposing obstacles to its reading remembers the censure of Galileo made by the Inquisition. The censure followed the failure to obtain the informed consent (IC) to disclose results of old samples. At present, the use of collected data or samples for a new research needs a new IC, in most ethical protocols. The Helsinki Code allows the research ethics committees the authorization for the use of that information. This norm is founded rather in commercial, legal or protective arguments than in ethical bases. This article criticizes this norm from the Scientific Ethics viewpoint because: i) the ownership of the genome and environment that originate a person is not of such person but of the human society and Homo sapiens species, ii) a person is not the unique owner of that information; laboratories, institutions, health services and research teams add constituents to it, iii) several violations to this norm occurring in medical, labor, legal and social practice show it as biased against science, iv) if this stored information and its use are beneficial for humankind (its proper owner) it is ethically obligatory to use it. It is proposed to create an anonymous World Bank for Human Information with open access and universal transparency. This universal collection of data handled under universal accepted ethical norms should prevent exclusive private use of public information, non-publication of negative results, illicit and unethical use of human data.

(Rev Med Chile 2012; 140: 390-395).

Key words: Bioethical issues; Genome, human; Hominidae.

L a censura de un trabajo científico publicado en 2008 con superposición de páginas con $\checkmark$ una nota de los autores retractándose por no contar con la certificación del Comité Revisor Institucional, al no conseguir el consentimiento informado (CI) de los dadores de las muestras antiguas ${ }^{1-3}$, rememora la censura de la Inquisición a las obras de Galileo ${ }^{4}$. Esta censura parece exagerada y con reparos éticos, pues la exigencia de CI para el uso anónimo de datos o materiales de seres humanos colectados no está fundada éticamente; pero, censurar el conocimiento es éticamente negativo. Desde la perspectiva de Ética Científica (EC), distinta de la Filosofía Moral, la Ética Clásica, la Ética Médica o la Bioética, fundamentamos aquí una propuesta diferente.

\section{Brevia sobre Ética Científica}

La EC ${ }^{5-11}$ se basa en el conocimiento humano (perceptivo, intuitivo, científico, de fe, etc.) sobre la naturaleza humana. No se basa en el a priori sobre la naturaleza humana que ideologías, religiones, filosofías, gnoseologías o racionalizaciones creen o suponen (ej. ser humano con cuerpo y alma, ser humano superior a otros seres). Para la EC el ser humano es un sub-proceso del proceso evolutivo universal, producto de la interacción genómicaambiental. La EC considera el núcleo primario de la Ética que es sentido de movimiento ${ }^{12}$, y no es antrópica (basada en el ser humano); el mundo inanimado tiene sentido de movimiento: los procesos de partículas van desde una ordenación (no 
azarosa) a una azarosa, por lo que la segunda ley de la termodinámica es un principio ético. La EC estudia los procesos neuropsíquicos de las decisiones, ideologías y creencias. La EC acepta el Código de Ética de la Sociedad de Biología de Chile ${ }^{13}$, cuyos dos primeros artículos son: Art. 1 La Sociedad de Biología de Chile declara su respeto y valoración positiva a toda forma de vida y se involucra en la preservación y mejora de las condiciones de vida en la Tierra. Art. 2 La Sociedad de Biología de Chile declara su vocación de estudiar, conocer, comprender, explicar, entender científicamente los procesos bióticos.

En esta discusión la EC difiere de otras éticas en dos consideraciones cruciales. I) La EC valora el conocimiento en sí y no por su utilidad creída o estimada por el ser humano. II) La EC considera como elemento crítico para el juicio ético a la población y en este caso a la especie Homo sapiens (no sólo al individuo). El proceso evolutivo y las especies (grupos o poblaciones) originaron al ser humano y no el ser humano originó a la especie o a las poblaciones. En lo que sigue colecciones de datos o muestras de seres humanos son todos los colectados en servicios clínicos (incluidas las fichas clínicas), consultas médicas públicas o privadas, laboratorios, instituciones de investigación científica, antropológica, sociológica, histórica o periodística, universidades u otros organismos en que estos datos o muestras se colecten. Para la EC persona no pertenece al lenguaje científico sino al ideológico, religioso, teológico o filosófico ${ }^{4-11}$. Se usa aquí como sinónimo de ser o individuo humano para entenderse en un contexto más amplio.

\section{Norma en el Código de Helsinki}

Aunque no todos los países aceptan el Código de Helsinki (CHel) y se atienen a sus propias normativas (guidelines), todos exigen, desde hace poco, el CI para utilizar datos o muestras colectadas de seres humanos en investigaciones o atenciones médicas previas. En el artículo pertinente la última revisión del CHel (Seúl 2008) dice “25. Para la investigación médica en que se utilice material o datos humanos identificables, el médico debe pedir normalmente el consentimiento para la recolección, análisis, almacenamiento y reutilización. Podrá haber situaciones en las que será imposible o impracticable obtener el con- sentimiento para dicha investigación o podría ser una amenaza para su validez. En esta situación, la investigación sólo puede ser realizada después de ser considerada y aprobada por un comité de ética de investigación"14. Aquí "identificable" no es preciso. Todo dato o muestra conservados deben permitir identificar a la persona dadora, ya que, si se descubre una solución para el problema que esa persona tiene, avalado por ese dato o muestra es imperioso ubicarla para tratarla. Para la EC "identificable" es el "acceso a los nombres y apellidos de las personas con fines de ubicarlas para requerir de ellas información necesaria para el nuevo objetivo". La norma actual (NA) es distinta ya que exige la ubicación de esas personas para requerir su CI cualquiera sea el nuevo procedimiento aunque no se necesite ningún dato nuevo de ella y sea anónimo. La distinción es crucial ya que la NA no está justificada ni éticamente ni científicamente. El uso de datos anónimos no vulnera la vida, salud, integridad, derechos, intimidad, confidencialidad, ni ninguna otra condición humana establecida en el Artículo 11. Al contrario el no usar datos de los cuales puede extraerse conocimiento es un atentado contra todas esas condiciones puesto que puede ignorar situaciones críticas para la vida humana.

\section{Carencia de fundamentos éticos de la exigencia de CI para el uso de material coleccionado}

Encuestando a decenas de científicos y miembros de tres comités de ética de la investigación he confirmado esta ausencia de fundamentos éticos propiamente tales. Los argumentos provienen de la prevención para no usar comercialmente esos datos o muestras (patentar) o legalmente (juicios por mala práctica), o de la posibilidad de identificación de las personas (filtraciones de datos) para que las empresas que las contratan o las aseguran puedan rechazarlas o fijar tarifas. Así, los fundamentos de esta medida son comerciales, administrativos o legales, pero no éticos. Es falta a la Ética transformarla en un conjunto de normas para prevenir juicios legales o provecho comercial. ¿De que Ética proviene entonces esta norma? El fundamento ético parece tener dos supuestos implícitos. A) Todo dato o muestra proveniente de una persona es propiedad de esa persona; B) el CI de esa persona autoriza a utilizar sus datos o muestras sólo para esa investigación (corolario de A). 


\section{A) Una muestra o dato de una persona no es propiedad sólo de ella}

Desde la EC el primer supuesto es erróneo y dado que el segundo depende de él justificaremos primero esta proposición.

i) Según la EC cada ser humano (ser vivo) es un proceso-producto de su interacción genómicaambiental; tanto su genoma (ser específico) como su ambiente no le pertenecen, sino que le han sido dados y pertenecen al proceso de evolución cósmica, de evolución orgánica de la Tierra y de evolución de la especie (Homo sapiens, aquí sinónimo de humanidad). Su ambiente específico histórico corresponde mayormente a lo que la humanidad ha hecho y más particularmente a lo que su familia, o grupo social le ha dado. Siendo el ser humano construido por la interacción dinámica de su genoma (aportado por sus progenitores y no por él) y su medio-ambiente (bio-psico-sociocultural) que el recibe y mayormente no construye (salvo por decisiones que va tomando), todo dato, muestra o resultado procedente de esta interacción le pertenecen más que a él a la humanidad.

ii) En la génesis de un dato o muestra (incluida la ficha clínica) intervienen la persona de quien proceden los datos o muestras, el equipo científico o de salud que prescriben, procesan información o las muestras, quienes almacenan, mantienen y resguardan la confidencialidad, etc. Además participan servicios agregados, secretariales, administrativos y logísticos imprescindibles para su registro y conservación. En estos procesos hay propiedad intelectual, administrativa y legal en la responsabilidad de la adquisición, tenencia, mantención, manejo, acceso, uso y confidencialidad de las muestras y datos.

\section{B) La restricción del CI, hecha por el dador} de muestras o datos, a los objetivos precisos de una intervención o investigación es en gran parte arbitraria y puede hacerse sólo para investigaciones cuyos objetivos son acotados

i) Restricción a investigaciones clínicas acotadas. Tanto el Código de Helsinki como las Guías se aplican a investigaciones clínicas acotadas a medicamentos, exámenes de laboratorio, nuevas tecnologías y en general a investigación en innovaciones médicas (IIM). Esto no es investigación científica propiamente tal sino que investigación técnica o tecnológica. No se trata del conocimiento sobre la naturaleza física, biótica, psíquica o social (normal o patológica) del ser humano, sin aplicaciones al momento en que la investigación se realiza. Esta es investigación básica en humanos (IBH), en la que es difícil señalar un objetivo, fuera de obtener cierto conocimiento, y aún eso puede ser pretencioso. Sin embargo, para que la IIM sea seria también tiene que estar abierta a encontrar reacciones inesperadas, serendipia (del inglés serendipity, encuentro fortuito de un resultado valioso no buscado) y tener que cambiar los objetivos de la investigación aunque la innovación ya haya cumplido su fase preclínica. Nuestra posición es que el paciente y el investigador, en beneficio del conocimiento sobre la humanidad que es propiedad de ella, no están en condiciones éticas de restringir el uso de la información que pudiera surgir del estudio de sus muestras o datos, aun en el caso de no salirse del protocolo sometido a consentimiento. Se olvida a menudo que toda ética es dependiente de la epistemología (conocimiento demostrado) en la que se inserta. El investigador científico, que no está atento a todo detalle de la investigación de tal modo de situarlo en la matriz disciplinaria (paradigma) ${ }^{15}$ y ver si ella o parte de ella se confirma, refuta o modifica, no acredita como investigador y lo que realiza no es buena investigación científica y por lo tanto, no es ética. Supongamos que las muestras, y sólo ésas, que originaron la investigación cuyo resultado fue censurado en cuanto a llegar a ser conocido públicamente contuvieran la información necesaria para resolver el problema de la leucemia mieloide aguda u otro no relacionado con ella, sería una falta ética grave negarle a la humanidad esa información; y aunque aportara un modesto conocimiento sería también falta ética impedir que ese conocimiento válidamente adquirido llegue a la humanidad. De allí que en toda investigación científica en el ser humano, y por honestidad con el proceso científico, el CI debería ser muy amplio y abierto a futuras investigaciones de las cuales no se puede saber su contenido. La única restricción ética a esta autorización es que esos estudios sean anónimos en relación al uso de la identidad de las personas donantes de muestras o datos. La aplicación de la norma de CI para una nueva investigación, sobre datos colectados, en forma estricta y absoluta, lleva al absurdo y hasta ridículo de impedir que un resultado ya publicado pueda ser interpretado de otra forma y dar conclusiones muy distintas a las presentadas. 
ii) Incoherencia e inconsistencia ética con investigaciones científicas, periodísticas, $u$ otras. Esta exigencia de CI o revisión por un comité no se aplica en otros tipos de investigaciones en seres humanos como ser las educacionales, sociales, periodísticas, antropológicas, judiciales, policiales, donde se aplican encuestas o se hacen interrogatorios. Raras veces las encuestas directas pasan por un comité y el CI no se exige porque se supone que el entrevistado da voluntariamente su consentimiento al acceder a contestar la encuesta. Las encuestas de opinión (sobre políticos, gobernantes, etc) no pasan por comités. Los contenidos y formatos para los interrogatorios policiales, judiciales, de espionaje $\mathrm{e}^{16}$ y periodísticos tampoco pasan por comités y se realizan sin CI. Hay estudios epidemiológicos en los que nunca se ha exigido CI y se tiene acceso a los nombres y apellidos de las personas (Ej. Estadísticas vitales, datos censales, determinación de parámetros poblacionales con muestras de laboratorios, estadísticas de servicios y laboratorios, etc). Las encuestas de opinión y los informes periodísticos, pueden ser usados y re-usados para diferentes fines sin CI.

\section{Inconsistencia con situaciones donde el CI debe ser obligatorio y este no se realiza}

i) El médico que trabaja en urgencia interviene a menudo sin el CI al ser la situación de tal urgencia que detenerse a hacerlo sería negligencia o imprudencia, o bien el paciente se encuentra imposibilitado. Así, la misma situación amerita no tomarlo; entonces se concluye que el CI no es absoluto sino que es relativo a la circunstancia.

ii) A veces el cirujano, al que el paciente ha dado su CI para una intervención, se encuentra con una complicación que requiere desarrollar otra muy distinta y no toma el CI. No se hace tampoco un CI amplio que autorice al cirujano a cualquier intervención. Esto es similar a la investigación científica que se encuentra con resultados que obligan a cambiar su contenido (hipótesis, objetivos, etc).

iii) En la legislación, varios países han construido bases de datos genómicos para delincuentes o presuntos delincuentes sin su CI. No hay fundamento ético que sustente esta posición, se alude a la no convincente protección de la sociedad y aparece como medida fascista (autoritaria extrema) y con severas restricciones éticas. Se falta a la ética al suponer que una persona, que supuestamente ha delinquido, pierde la protección ética de su intimidad genómica, porque ha sido declarado reo (aunque la declaración sea errónea), lo que no es una connotación ética sino legal (hay un abismo entre la ética y la legalidad).

\section{Condiciones de CI insuficiente o inmoral}

i) En los ensayos clínicos realizados por las empresas no se incluye en el CI las condiciones comerciales de la innovación médica, ni la forma en que la persona donante participara en los beneficios económicos. Esto es un tema intocable aunque es lo más pertinente para la persona donante.

ii) El CI en los contratos laborales es insuficiente; a veces es francamente inmoral. Los trabajadores no reciben información sobre las condiciones legales o de seguridad en sus trabajos y así deben firmar los contratos. El caso de los mineros de Atacama mostró que trabajaban en una mina sin condiciones para hacerlo. El terre-mare-moto reciente del Japón mostró situaciones éticas críticas no cubiertas por el contrato de trabajo con reactores nucleares.

\section{Una nueva proposición desde la Ética Científica}

Como el genoma, las fichas clínicas, los datos y muestras de una persona no le pertenecen como único propietario ya que él es un proceso emergido de la evolución biótica, psico-sociocultural y ambiental, proponemos que todo dato o muestra humana vaya a un repositorio o banco de datos universales, propiedad de la Humanidad. Toda investigación (que sea epistémicamente válida) nueva sobre estos datos o muestras realizada anónimamente es éticamente, no sólo aceptable sino que obligatoria en el entendido que el conocimiento que de ella se genere también será patrimonio de la humanidad y difundido universalmente. La Humanidad (OMS, UN) se hace cargo de los datos y de toda la investigación sobre la humanidad y controla éticamente toda investigación sobre la humanidad. Para esto tendrá los grupos más preparados de científicos, metodólogos, estadísticos, comités de ética, etc. Los grupos públicos (universidades, organismos nacionales) o privados (empresas) harán investigaciones compartiendo copias de todos los datos con este centro mundial, que determinará lo patentable o no patentable; todo resultado será público para toda la humanidad; así se evita investigaciones de 
las que nunca se da cuenta, que no se publiquen resultados negativos, y los datos quedan disponibles para toda la humanidad. Toda observación en seres humanos se integra a este sistema universal de datos con identidades encriptadas. Los CI deberían incluir la autorización de guardar los datos en este sistema universal de investigación en el ser humano. El mismo sistema tiene Comités Éticos universalmente reconocidos con una normativa y factualidad de acción transparente para todos.

\section{Gravedad de lo ocurrido con la censura del artículo mencionado}

Censurar el conocimiento adquirido por la humanidad, producir ignorancia, obstaculizar la obtención de conocimiento son faltas éticas graves. Hay una confusión entre el contenido del conocimiento que está siendo censurado y la falta a la ética de los investigadores; ambos procesos pertenecen a diferentes planos del quehacer humano. Aun en las atrocidades nazis donde se hizo investigación en seres humanos vulnerables (campos de concentración) este principio se aplica. El conocimiento así obtenido es un logro valioso de la humanidad, que en vez de llenar de oprobio a esas víctimas las llena de gloria porque entregaron sus vidas dando conocimiento. El conocimiento no puede ser castigado. Los que se llenan de oprobio son los victimarios. Olvidar esos dolorosos pasajes de nuestra historia como seres humanos es un crimen ético que se agravaría con el olvido del conocimiento adquirido con la vida de las víctimas. Éticamente el olvido es siempre un defecto no una virtud; la pérdida de la memoria es una minusvalía de la persona y de la humanidad. Si toda muestra o dato procedente de la humanidad puede producir conocimiento y eventualmente ayudarle a solucionar un problema de salud o bienestar es un crimen impedirlo. Es un error confundir las complicaciones legales o comerciales del uso del conocimiento científico con la ética de la investigación que procura ese conocimiento. La utilización de los datos, muestras o resultados de la investigación científica en forma criminal siempre podrá hacerse pero eso no es ética de la investigación científica sino ética común ciudadana sujeta a la legislación civil y penal. No puede olvidarse que a pesar de lo lamentable que son los desastres de la naturaleza que tantas muertes y daños dejan y las guerras que ha precipitado la humanidad, el conocimiento producido por ellos ha sido fundamental para su desarrollo.

Es también grave que la fuente de la censura no se identifique. ¿Fue el Comité Ético? ¿El Comité Editorial? ¿El investigador? Censurar es una sanción que por ética debería emanar de un Tribunal Ético especializado en sanciones y ninguno de los comités mencionados o el investigador son tribunales. No existen tales tribunales. La Sociedad de Biología de Chile otorga al Directorio de la Sociedad la facultad de ser tribunal y ahí están claras las funciones, pero en el caso analizado no se sabe desde donde emanó la sanción. El Código de Helsinki otorga la potestad de autorizar el uso de muestras a los Comités Éticos locales pero esto es usurpación de funciones ya que esos comités no tienen tuición ni propiedad sobre las muestras. Son los directores de las instituciones donde se guardan los registros y muestras los que pueden autorizar su uso.

\section{Referencias}

1. Kobayashi S, Soda Y, Bai Y, Tojo A. Heterogeneous promoter activity of the telomerase reverse transcriptase gene in individual acute myeloid leukemia cells defined by lentiviral reporter assay. Haematologica 2008; 93: 1103-5.

2. Normile D. Old samples trip up Tokyo team. Science 2008; 321: 324

3. Normile D. Paper retraction puts focus on informed consent rules 2008; 321: 474.

4. http://es.wikipedia.org/wiki/Galileo_Galilei

5. Valenzuela CY. Verso un'etica scientifica: l'origine della individualità ed il problema degli embrioni congelati. En: Redi CA, Garagna S, Zuccotti M, Editores, Biologia delle cellule staminali oportunita e limiti di impiego. Como-Pavía (Collegio Ghislieri), Italia: Ibis; 2000, p. 33-45.

6. Valenzuela CY. Ética científica y embriones congelados. Rev Med Chile 2001; 129: 561-8.

7. Valenzuela CY. Ética científica del aborto terapéutico. Rev Med Chile 2003; 131: 562-8.

8. Valenzuela CY. Etica científica de la terapia génica de individuos. Urgencia de la cirugía génica del ADN. Rev Med Chile 2003; 131 1208-14.

9. Valenzuela CY. Ética científica de la clonación humana. Rev Med Chile 2005; 133: 105-12.

10. Valenzuela $\mathrm{CY}$. El riesgo de malformaciones congénitas y 
defectos de la programación genómica, en relación con las técnicas de reproducción asistida y la clonación. Rev Med Chile 2005; 133: 1075-80.

11. Valenzuela CY. Ética Científica del aborto en caso de anencefalia. Rev Med Chile 2011 (en revisión).

12. Rosales E. Hacia una moral social y profesional. Tomo I. Santiago, Chile, Prensas de la Editorial Universitaria; 1961. p. 20-4.

13. Valenzuela CY, Cruz-Coke R, Ureta T, Bull R. Código de ética de la Sociedad de Biología de Chile. Rev Med Chile 1997; 125: 71-3.

14. http://www.cei.fmed.edu.uy/archivos/05\%2020Declaracion_de_Helsinki_2008_ESPANOL.pdf

15. Kuhn T. The structure of scientific revolutions. $2^{\circ}$ Ed. Chicago, USA, The University of Chicago Press; 1970.

16. Palamarca HA. Ética y Servicios de Inteligencia. Valparaíso Chile. Imprenta de la Armada de Chile. Sin año, inscripción I.S.B.N. 956-7314-01-2. 